\title{
The role of a family history of psychosis for youth at clinical high risk of psychosis
}

\author{
Grace Georgopoulos $^{1}$ | Jacqueline Stowkowy ${ }^{1}$ | Lu Liu $^{1}$ | Kristin S. Cadenhead ${ }^{2}$ | \\ Tyrone D. Cannon ${ }^{3}$ | Barbara A. Cornblatt ${ }^{4}$ | Thomas H. McGlashan ${ }^{5}$ | Diana O. Perkins ${ }^{6}$ | \\ Larry J. Seidman ${ }^{7}$ | Ming T. Tsuang ${ }^{2,8}$ | Elaine F. Walker ${ }^{9}$ | Scott W. Woods ${ }^{5}$ | \\ Carrie E. Bearden ${ }^{10}$ | Daniel H. Mathalon ${ }^{11,12}$ | Jean Addington ${ }^{1}$
}

${ }^{1}$ Hotchkiss Brain Institute, Department of Psychiatry, University of Calgary, Calgary, Alberta, Canada

${ }^{2}$ Department of Psychiatry, University of California San Diego, La Jolla, California

${ }^{3}$ Department of Psychology, Yale University, New Haven, Connecticut

${ }^{4}$ Department of Psychiatry, Zucker Hillside Hospital, Queens, New York

${ }^{5}$ Department of Psychiatry, Yale University, New Haven, Connecticut

${ }^{6}$ Department of Psychiatry, University of North Carolina, Chapel Hill, North Carolina

${ }^{7}$ Department of Psychiatry, Harvard Medical School at Beth Israel Deaconess Medical

Center and Massachusetts General Hospital, Boston, Massachusetts

${ }^{8}$ Institute of Genomic Medicine, University of California, La Jolla, California

${ }^{9}$ Department of Psychology, Emory University, Atlanta, Georgia

${ }^{10}$ Departments of Psychiatry and Biobehavioral Sciences and Psychology, University of California, Los Angeles, Los Angeles, California

${ }^{11}$ Department of Psychiatry, University of California, San Francisco, San Francisco, California

${ }^{12}$ Psychiatry Service, San Francisco, California

Correspondence

Dr Jean Addington, Mathison Centre for Mental Health Research \& Education, University of Calgary, 3280 Hospital Drive NW, Calgary, AB T2N 4Z6, Canada.

Email: jmadding@ucalgary.ca

Funding information

National Institute of Mental Health, Grant/ Award number: U01MH08185705
Aim: On average, there is a $10 \%$ to $12 \%$ likelihood of developing a psychotic disorder solely based on being at familial high risk. However, the introduction of the criteria for clinical high risk (CHR) of psychosis suggested for CHR individuals, $20 \%$ to $30 \%$ will go on to develop a fullblown psychotic illness within 3 years. Several studies suggest a role for family history in conversion to psychosis among those at CHR. However, we know very little about those who meet the CHR criteria and have a positive family history for psychosis compared to those at CHR with no known family history. The aim of this study was to compare these 2 groups on demographics, clinical symptoms, social and role functioning, IQ, environmental factors and conversion to psychosis.

Method: A total of 762 participants met criteria for being at CHR, 119 of whom had a family history $(\mathrm{CHR}+\mathrm{FH})$ and 643 without $(\mathrm{CHR}-\mathrm{FH})$. Groups were compared on attenuated symptoms, role and social functioning, IQ, past trauma, perceived discrimination and cannabis use. Survival analysis was used to compare groups on conversion rates.

Results: There were no major differences between the groups in symptoms, functioning, IQ, cannabis use or in the rate of conversion between the groups. The $\mathrm{CHR}+\mathrm{FH}$ group reported increased amounts of early trauma.

Conclusion: There is a possibility that $\mathrm{CHR}+\mathrm{FH}$ individuals believe that it is more difficult for them to cope with circumstances such as abuse or potential abuse. Future research on this subject should investigate family environment and its role in conversion to psychosis among $\mathrm{CHR}+\mathrm{FH}$ individuals.

KEYWORDS

family risk, prodromal, psychosis 


\section{1 | INTRODUCTION}

Research suggests that on average there is a $10 \%$ to $12 \%$ likelihood of developing a psychotic disorder solely based on being at familial high risk (Gottesman \& Erlenmeyer-Kimling, 2001; Lewis, Reveley, Reveley, Chitkara, \& Murray, 1987). However, the introduction of the clinical high risk (CHR) criteria of psychosis based on early signs of subthreshold or attenuated psychotic symptoms, started a new era of high risk research in psychosis. These are individuals experiencing attenuated psychotic symptoms, and/or brief limited full-blown psychotic symptoms, and/or a significant decrease in functioning that coincides with a genetic risk (McGlashan, Walsh, \& Woods, 2010). Of those identified as being at CHR of psychosis, $20 \%$ to $30 \%$ will go on to develop a full-blown psychotic illness within 3 years (Fusar-Poli et al., 2012).

In the epidemiological literature, it has been suggested that risk factors such as history of childhood trauma, migration, perceived discrimination, urban upbringing and cannabis use may be associated with the future onset of psychosis (Cantor-Graae \& Selten, 2005; Read, van Os, Morrison, \& Ross, 2005; van Os, Kenis, \& Rutten, 2010; Veling et al., 2007). However, a comprehensive review concluded that evidence is accumulating demonstrating that these environmental exposures have an impact on the risk of psychosis in conjunction with inherited risk genes and that the impact of environmental or inherited risk genes on their own are minimal (van Os, Rutten, \& Poulton, 2008). Second, there are a few studies suggesting a role for a family history of psychosis in later conversion to psychosis for those at $\mathrm{CHR}$, namely in conjunction with a deterioration in functioning, unusual thoughts and substance use (Bora \& Murray, 2013; Cannon et al., 2008), with neurocognition (Addington et al., 2007; Seidman et al., 2010) and with psychosis proneness (Tandon et al., 2012). Thus, such synergistic relationships suggest that possible combinatory effects may occur when known psychosis risk factors and a family history of psychosis coincide. However, we know very little about those who meet $\mathrm{CHR}$ criteria and have a positive family history for psychosis compared to those at $\mathrm{CHR}$ with no known family history.

The purpose of this study was to determine if there are differences between CHR individuals who have or do not have a family history of psychosis. The first aim was to compare these 2 groups on demographics, clinical symptoms, social and role functioning, IQ and environmental factors (cannabis use, trauma and perceived discrimination) previously reported as risk factors for psychosis. Second, the groups were compared on rates of conversion to psychosis.

\section{2 | METHODS}

\section{1 | Participants}

Participants were recruited as part of the multi-site NIMH-funded North American Prodrome Longitudinal Study 2 (NAPLS-2) at all 8 NAPLS-2 sites (Emory University, Harvard University, University of Calgary, UCSD, UCLA, UNC at Chapel Hill, Yale University and Zucker-Hillside Hospital).
The overall NAPLS-2 sample consisted of $764 \mathrm{CHR}$ individuals (436 males and 328 females) who were help-seeking and were referred from health care providers, educators, social service agencies, or were self-referred in response to community educational efforts. Participants were evaluated using the Structured Interview for Psychosis-risk Syndromes (SIPS; McGlashan et al., 2010) to determine if they met criteria for one or more of the following high risk syndromes: attenuated psychotic symptoms syndrome (APSS), brief intermittent psychotic symptoms syndrome (BIPS) or genetic risk and deterioration syndrome (GRD). Two participants did not have details on family history and were thus excluded from this study. The final sample for this study consisted of $762 \mathrm{CHR}$ individuals who met Criteria of Prodromal Syndromes (COPS). Individuals were considered high risk if they met COPS criteria, or if they were under the age of 18 and met schizotypal personality disorder. A total of 741 participants met COPS criteria, and an additional 21 were considered high risk due to the presence of schizotypal features and being under the age of 18. Participants had to be between 12 and 35 years of age. Participants were excluded from the study if they met criteria for any current or lifetime axis I psychotic disorder, had an IQ below 70 or had a past or current history of a clinically significant central nervous system disorder. We have previously reported a more detailed description of recruitment procedures, ascertainment and inclusion and exclusion criteria (Addington et al., 2012).

One hundred and nineteen had a first degree relative with a history of psychosis $(\mathrm{CHR}+\mathrm{FH})$ and 643 had no family history (CHR-FH).

\section{2 | Measures}

The SIPS and the Scale of Prodromal Symptoms (SOPS; McGlashan et al., 2010) were used to determine the criteria for a prodromal syndrome and to determine severity of prodromal symptoms (19 items in 4 symptom domains; ie, positive, negative, general and disorganized symptoms). The presence of a first-degree relative with psychosis was determined with The Family Interview for Genetics Studies (FIGS; Maxwell, 1996), severity and frequency of cannabis use in the last month with the Alcohol and Drug use Scale (AUS/DUS; Drake, Mueser, \& McHugo, 1996), and functioning with the Global Functioning Scale: Social (GF:S) and the Global Functioning Scale: Role (GF:R) (Cornblatt et al., 2007). The Perceived Discrimination Scale (Janssen et al., 2003) was used to determine whether participants felt they had experienced discrimination over their lifetime because of skin colour, ethnicity, gender, age, appearance, disability, sexual orientation or religion. The Childhood Trauma and Abuse Scale (Janssen et al., 2004) examined trauma and abuse with regard to emotional neglect, and psychological, physical or sexual abuse before age 16 . The Wechsler Abbreviated Scale of Intelligence (WASI) was used to assess IQ.

\section{3 | Procedures}

The study was approved by the Institutional Review Boards of all 8 NAPLS-2 sites. Written informed consent, including parental consent, was obtained from all adult participants and parents/guardians of 
TABLE 1 Demographic characteristics

\begin{tabular}{|c|c|c|c|}
\hline Variable & $\begin{array}{l}\mathrm{CHR}+\mathrm{FH} \\
n=119\end{array}$ & $\begin{array}{l}\text { CHR-FH } \\
n=643\end{array}$ & Test statistic \\
\hline & \multicolumn{2}{|c|}{ Mean (SD) } & $t$ Score \\
\hline Age & $19.34(4.83)$ & $18.36(4.10)$ & $-2.08 *$ \\
\hline \multirow[t]{2}{*}{ Years of education } & $11.42(2.49)$ & $11.26(2.84)$ & -0.57 \\
\hline & \multicolumn{2}{|c|}{$N(\%)$} & $X^{2}$ \\
\hline \multicolumn{4}{|l|}{ Sex } \\
\hline Female & 59 (49.6\%) & 267 (41.5\%) & \\
\hline \multicolumn{4}{|l|}{ Race } \\
\hline Asian & $8(6.8 \%)$ & $45(6.9 \%)$ & 8.27 \\
\hline West/Central Asia/Middle East & $2(1.7 \%)$ & $5(0.8 \%)$ & \\
\hline White & 77 (64.7\%) & 359 (55.9\%) & \\
\hline Other & $2(1.7 \%)$ & $14(2.2 \%)$ & \\
\hline \multicolumn{4}{|l|}{ Marital status } \\
\hline Single never married & $109(91.6 \%)$ & 609 (95.5\%) & 6.98 \\
\hline Married/Common law & $4(3.4 \%)$ & $8(2.9 \%)$ & \\
\hline Living with significant other & $3(2.5 \%)$ & 5 (1.8\%) & \\
\hline Currently enrolled as a student & 92 (77.3.0\%) & 531 (83.4\%) & 2.53 \\
\hline \multicolumn{4}{|l|}{ Family history relation } \\
\hline Mother & 37 (31.1\%) & N/A & N/A \\
\hline Father & 39 (32.8\%) & $\mathrm{N} / \mathrm{A}$ & \\
\hline
\end{tabular}

${ }^{*} P<.05$.

minors. After the initial screening, vignettes were developed for each participant and presented on a weekly consensus call, chaired by $\mathrm{Dr}$ Jean Addington and attended by the clinical raters from each of the 8 sites. Submitted vignettes were individually reviewed, and a consensus was reached on each symptom rating, diagnosis and ultimate admission into the study. Clinical raters were experienced research clinicians. Gold standard post-training agreement on determining the prodromal diagnoses was excellent ( $\kappa=0.90$; Addington et al., 2012).

\section{4 | Statistical analysis}

Groups were compared using independent $t$-tests for continuous variables and $\chi^{2}$ for percentages. Kaplan-Meier was used to estimate the survival function for time to onset of psychosis for both the $\mathrm{CHR}+\mathrm{FH}$ and the $\mathrm{CHR}-\mathrm{FH}$ groups.

\section{3 | RESULTS}

There were $762 \mathrm{CHR}$ participants (436 males and 326 females). The majority of the sample was white, were students and lived at home. One hundred and nineteen had a first degree relative with a history of psychosis and 643 did not. Among those with a family history, the majority had a mother or father with psychosis. The $\mathrm{CHR}+\mathrm{FH}$ group was significantly older than the $\mathrm{CHR}-\mathrm{FH}$ group; otherwise there were no other demographic group differences. Baseline demographics are presented in Table 1. Information of the breakdown of diagnostic categories is presented in Table 2 .

Comparisons between the groups are presented in Table 3. $\mathrm{CHR}-\mathrm{FH}$ individuals had higher severity ratings on total attenuated psychotic symptoms, specifically unusual thought content and perceptual abnormalities. However, 27 of the $\mathrm{CHR}+\mathrm{FH}$ individuals met only GRD criteria for being at CHR. When this group was removed

TABLE 2 Prodromal diagnostic criteria

\begin{tabular}{lcc} 
Prodromal criteria & Number & $\%$ \\
\hline $\begin{array}{l}\text { Attenuated Psychotic Symptom Syndrome } \\
\text { (APSS) }\end{array}$ & 641 & 83.8 \\
$\begin{array}{l}\text { Genetic Risk and Deterioration (GRD) } \\
\begin{array}{l}\text { Brief Intermittent Psychotic Symptoms } \\
\text { (BIPS) }\end{array}\end{array}$ & 34 & 4.4 \\
Under 19 plus Schizotypy & 21 & 0.8 \\
APSS plus GRD & 48 & 2.7 \\
\hline APSS plus BIPS & 12 & 6.3 \\
\hline BIPS plus APSS plus GRD & 2 & 1.6 \\
\hline Total & 764 & 0.3 \\
\hline
\end{tabular}


TABLE 3 Group comparisons

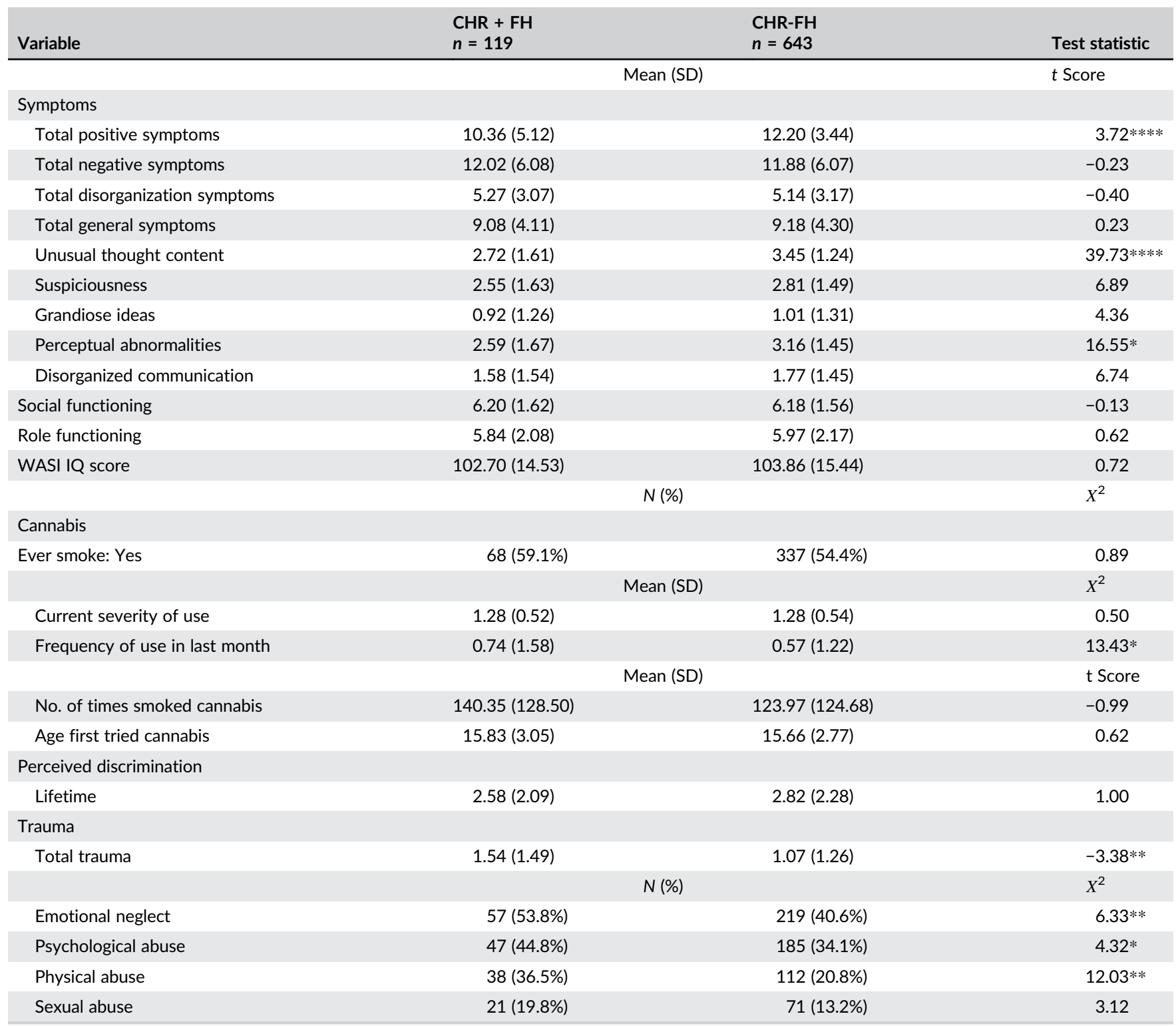

$* P<.05, * * P<.01, * * * P<.001, * * * * P<.0001$.

from the $\mathrm{CHR}+\mathrm{FH}$ there were no differences between the groups in attenuated positive symptoms (Table 4). Compared to $\mathrm{CHR}-\mathrm{FH}$, the $\mathrm{CHR}+\mathrm{FH}$ group reported increased trauma (emotional neglect, psychological abuse and physical abuse). Although the $\mathrm{CHR}+\mathrm{FH}$ reported a higher frequency of cannabis use within the month preceding the assessment, the groups did not differ on past history of use, age when they first used or severity of use. There were no statistical differences between the 2 groups in functioning, perceived discrimination or IQ. As the groups differed on age and trauma we conducted multinomial logistic regression to control for age, trauma and the interaction between age and trauma. Results of this interaction testing indicated that the interaction effect has no impact on the results of the univariate group comparisons.

Of the $85 \mathrm{CHR}$ participants who converted to psychosis during the 2-year study period, 17 were $\mathrm{CHR}+\mathrm{FH}$ (14.3\%), and 68 were $\mathrm{CHR}-\mathrm{FH}$ (10.6\%). The cumulative incidence rates of transition to psychosis during the follow-up period were estimated with Kaplan-Meier survival analysis.

TABLE 4 Group comparisons of symptoms with GRD group removed

\begin{tabular}{lcll} 
Variable & $\begin{array}{l}\text { CHR + FH } \\
\mathbf{n = 1 1 9}\end{array}$ & $\begin{array}{l}\text { CHR-FH } \\
\mathbf{n = 6 4 3}\end{array}$ & $\begin{array}{l}\text { Test } \\
\text { statistic }\end{array}$ \\
\hline $\begin{array}{c}\text { Mean (SD) } \\
\begin{array}{c}\text { Total positive } \\
\text { symptoms }\end{array}\end{array}$ & $12.14(4.08)$ & $12.20(3.44)$ & 0.15 \\
$\begin{array}{c}\text { Unusual thought } \\
\text { content }\end{array}$ & $3.18(1.44)$ & $3.45(1.24)$ & 1.94 \\
\hline $\begin{array}{c}\text { Perceptual } \\
\text { abnormalities }\end{array}$ & $3.09(1.44)$ & $3.16(1.45)$ & 0.48 \\
\hline \begin{tabular}{l} 
abnore \\
\hline
\end{tabular} & & & \\
\hline
\end{tabular}

Figure 1 presents the Kaplan-Meier estimate of the survival function for time to onset of psychosis for both groups. For the CHR-FH group, the mean time from baseline to conversion to psychosis was 198.5 days ( $S D=168.09$, median $=154.0$ ). The cumulative incidence rate of conversion was $12.71 \%$ for year 1 (SE $=0.0168,95 \% \mathrm{Cl}=$ 0.0981-0.1647). For the CHR + FH group, the mean time from baseline to conversion to psychosis was 274.9 days $(S D=146.36$, 


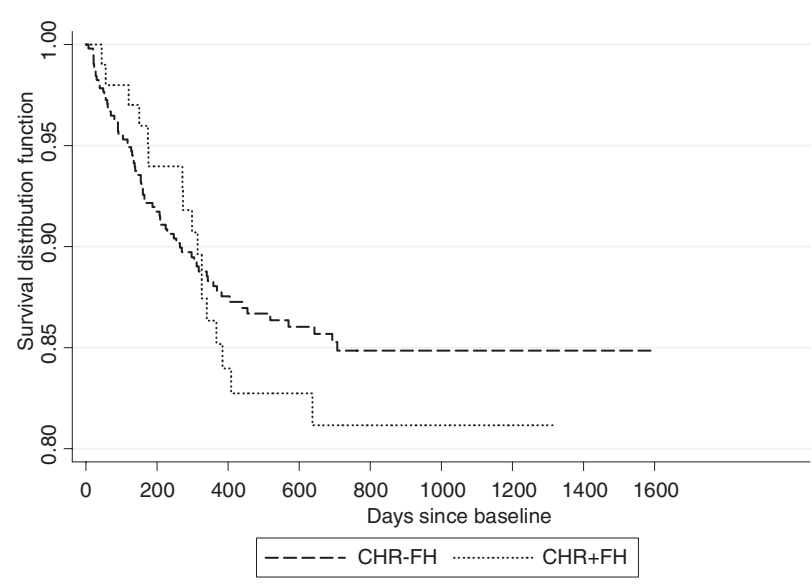

FIGURE 1 Kaplan-Meier estmates of the cumulative survival for $\mathrm{CHR}-\mathrm{FH}$ and $\mathrm{CHR}+\mathrm{FH}$ groups

median $=299.0$ ). The cumulative incidence rate of conversion was $14.61 \%$ for year 1 (SE $=0.0407,95 \% \mathrm{Cl}=0.0847-0.2521$ ).

The 2 survival curves cross each other near 300 days since baseline. Thus, $\mathrm{CHR}+\mathrm{FH}$ individuals experience lower rates of conversion to psychosis than the $\mathrm{CHR}-\mathrm{FH}$ individuals in the early period; however, in the later period, $\mathrm{CHR}+\mathrm{FH}$ individuals experience greater rates of conversion to psychosis than $\mathrm{CHR}-\mathrm{FH}$ individuals. We performed the Peto-Peto-Prentice test of equality for the 2 groups. This test is appropriate when hazard functions are thought to vary in ways other than proportionally. The tests conclude that the survival rates in the 2 groups are not significantly different $(P=.5636)$.

\section{4 | DISCUSSION}

The purpose of this paper was to examine in a large CHR sample clinical differences between those who have a family history and those who do not. Approximately $16 \%$ had a family history of psychosis with the most common relative being a mother or a father. Those without a family history tended to be younger, and had increased ratings on attenuated positive symptoms. However, this seemed to be a function of the fact that all participants who met only GRD criteria would be in the $\mathrm{CHR}+\mathrm{FH}$ group. After those 27 participants were removed the 2 groups no longer differed on attenuated psychotic symptoms. That is those who had APSS plus a family history did not differ from those with APSS and no family history. Although those in the $\mathrm{CHR}+\mathrm{FH}$ reported using more cannabis in the past month, there were no other significant differences with respect to cannabis use. It is likely that although statistically significant, this difference in frequency is not clinically significant in that both means fall in the range of 1 to 2 times per month.

Thus, although some earlier studies did suggest a role for a family history of psychosis in later conversion to psychosis for those at CHR, but in conjunction with a deterioration in functioning, unusual thoughts and substance use, (Bora \& Murray, 2013; Cannon et al., 2008) and neurocognition (Addington et al., 2007; Seidman et al., 2010) we did not find that our $2 \mathrm{CHR}$ groups differed on those factors.

Current literature and reviews (Fusar-Poli et al., 2017; Gibson, Alloy, \& Ellman, 2016) have shown trauma to be an important risk factor among those at high risk of psychosis. Interestingly, although our sample all met criteria for being at CHR, we found a further distinction between those with and without a family history. The groups did differ on traumatic experiences prior to age 16 with the $\mathrm{CHR}+$ $\mathrm{FH}$ group reporting more experiences in all categories except sexual abuse. It is possible that growing up in a home where one parent may have a serious mental illness or may be absent due to that illness, may increase the risk for experiencing more trauma. It is possible that an individual who is vulnerable to psychosis may not have the necessary skills or available resources to get help with potential abuse or may just perceive themselves to be disadvantaged. This fits with previous research reporting an association between a positive family environment and lower prevalence of psychosis in those at genetic risk (Gonzalez-Pinto et al., 2011), and an increased impact of a family environment for those with a biological predisposition to psychosis (O'Brien et al., 2006; Tienari et al., 2004). A recent epidemiological study provides strong evidence that it is the stress reaction which is the first sign of incipient psychosis. In this study, there was a positive interaction between trauma disorder and family history of schizophrenia on the subsequent incidence of schizophrenia in dually affected individuals (Okkels, Trajbjerg, Arendt, \& Perdersen, 2017). Additionally, a recent review has summarized some biological links between genes, stress and dopamine in the development of psychosis. The proposal is that there are a number of genetic risk factors which converge on the dopamine system, particularly, those involving glutamatergic systems. One possible model is that genes and environmental factors may sensitize the dopamine system so it is vulnerable to acute stress, leading to dysregulation and eventually psychosis (Howes, McCutcheon, Owen, \& Murray, 2017).

There were no differences in conversion rates between the 2 groups. Interestingly, in an earlier study (Tandon et al., 2012) examining the risk of conversion in a sample of young people with a first or second degree relative with schizophrenia, the assessment of psychosis proneness had a high specificity and sensitivity in predicting the likelihood of a person already at risk developing a psychotic disorder over a 2-year period. However, in this family high risk sample 17 participants met criteria for being "prone to psychosis" of whom 10 converted to psychosis which is very high relative to our sample. There are clear differences in the studies in that in the Tandon study they started with a Family High Risk (FHR) sample with well diagnosed probands whereas in our sample we started with those at CHR and examined reported family history of any psychotic disorder. For our sample, it may have been that having a family history of psychosis was a vulnerability factor for developing attenuated psychotic symptoms versus being a vulnerability factor for transitioning from a high risk state to psychosis.

The strength of this study is that it is a large sample. However, there are limitations. We do not know the specific diagnoses of the affected family member only that they had a definite psychotic illness. We do not have an assessment of the family environment and make assumptions that growing up with an ill parent or sibling has an impact on family environment or at least the individual's perception of it. We do not know if help-seeking varies between the 2 groups or that those with a family history are more or less likely to seek help. 
In conclusion, this is, to the best of our knowledge, the first study to examine differences between CHR individuals with and without a family history of psychosis. Future studies should investigate the family environment of those at CHR. Furthermore, although a family environment may be poor before the onset of psychosis, it can actually become worse with the progression of the illness (O'Brien et al., 2006). Thus, clinical implications are that any effort to improve the family environment for those at CHR especially those with a family history would be beneficial.

\section{REFERENCES}

Addington, J., Cadenhead, K. S., Cannon, T. D., Cornblatt, B., McGlashan T. H., Perkins, D. O., ... Heinssen, R., (2007). North American Prodrome Longitudinal Study: A collaborative multisite approach to prodromal schizophrenia research. Schizophrenia Bulletin, 33, 665-672.

Addington, J., Cadenhead, K. S., Cornblatt, B. A., Mathalon, D. H., McGlashan T. H., Perkins, D. O., ... Cannon, T. D., (2012). North American Prodrome Longitudinal Study (NAPLS 2): Overview and recruitment. Schizophrenia Research, 142, 77-82.

Bora, E., \& Murray, R. M. (2013). Meta-analysis of cognitive deficits in ultra-high risk to psychosis and first-episode psychosis: Do the cognitive deficits progress over, or after, the onset of psychosis? Schizophrenia Bulletin , 40, 744-755.

Cannon, T. D., Cadenhead, K., Cornblatt, B., Woods, S. W., Addington, J., Walker, E., ... Heinssen, R., (2008). Prediction of psychosis in youth at high clinical risk: A multisite longitudinal study in North America. Archives of General Psychiatry, 65, 28-37.

Cantor-Graae, E., \& Selten, J. P. (2005). Schizophrenia and migration: A meta-analysis and review. The American Journal of Psychiatry, 162, 12-24.

Cornblatt, B. A., Auther, A. M., Niendam, T., Smith, C. W., Zinberg, J., Bearden, C. E., \& Cannon, T. D. (2007). Preliminary findings for two new measures of social and role functioning in the prodromal phase of schizophrenia. Schizophrenia Bulletin, 33, 688-702.

Drake, R. E., Mueser, K., \& McHugo, G. (1996). Clinical rating scales. In L. Sederer \& B. Dickey (Eds.), Outcomes assessment in clinical practice (pp. 113-116). Baltimore, MD: Williams and Wilkins.

Fusar-Poli, P., Bonoldi, I., Yung, A. R., Borgwardt, S., Kempton, M. J., Valmaggia, L., ... McGuire, P. (2012). Predicting psychosis: Meta-analysis of transition outcomes in individuals at high clinical risk. Archives of General Psychiatry, 69, 220-229.

Fusar-Poli, P., Tantardini, M., De Simone, S., Ramella-Cravaro, V., Oliver, D., Kingdon, J., ... Kotlicka-Antczak, L. (2017). Deconstructing vulnerability for psychosis: Meta-analysis of environmental risk factors for psychosis in subjects at ultra high-risk. European Psychiatry, 40, 65-70.

Gibson, L. E., Alloy, L. B., \& Ellman, L. M. (2016). Trauma and the psychosis spectrum: A review of symptom specificity and explanatory mechanisms. Clinical Psychology Review, 49, 92-105.

Gonzalez-Pinto, A., Ruiz de, A. S., Ibanez, B., Otero-Cuesta, S., Castro-Fornieles, J., Graell-Berna, M., ... Arango, C. (2011). Can positive family factors be protective against the development of psychosis? Psychiatry Research, 186, 28-33.

Gottesman, I., \& Erlenmeyer-Kimling, L. (2001). Family and twin strategies as a head start in defining Prodromes and Endophenotypes for hypothetical early-interventions in schizophrenia. Schizophrenia Research, 51, 93-102.
Howes, O. D., McCutcheon, R., Owen, M. J., \& Murray, R. M. (2017). The role of genes, stress, and dopamine in the development of schizophrenia. Biological Psychiatry, 81, 9-20.

Janssen, I., Hanssen, M., Bak, M., Bijl, R. V., de Graaf, R., Vollebergh, W. ... van Os J. (2003). Discrimination and delusional ideation. The British Journal of Psychiatry, 182, 71-76.

Janssen, I., Krabbendam, L., Bak, M., Hanssen, M., Vollebergh, W., de Graff, R., \& van Os, J. (2004). Childhood abuse as a risk factor for psychotic experiences. Acta Psychiatrica Scandinavica, 109, 38-45.

Lewis, S. W., Reveley, A. M., Reveley, M. A., Chitkara, B., \& Murray, R. M. (1987). The familial/sporadic distinction as a strategy in schizophrenia research. The British Journal of Psychiatry, 151, 306-313.

Maxwell, M. E. (1996). FIGS: Clinical neurogenetics branch IRP (). Bethesda, MD: NIMH.

McGlashan, T., Walsh, B. C., \& Woods, S. W. (2010). The psychosis risk syndrome: Handbook for diagnosis and follow-up (). New York: Oxford University Press.

O'Brien, M. P., Gordon, J. L., Bearden, C. E., Lopez, S. R., Kopelowicz, A., \& Cannon, T. D. (2006). Positive family environment predicts improvement in symptoms and social functioning among adolescents at imminent risk for onset of psychosis. Schizophrenia Research, 81, 269-275.

Okkels, N., Trajbjerg, B., Arendt, M., \& Perdersen, C. B. (2017). Traumatic stress disorders and risk of subsequent schizophrenia Spectrum disorder or bipolar disorder: A nationwide cohort study. Schizophrenia Bulletin, 43(1), 180-186.

Read, J., van Os, J., Morrison, A. P., \& Ross, C. A. (2005). Childhood trauma, psychosis and schizophrenia: A literature review with theoretical and clinical implications. Acta Psychiatrica Scandinavica, 112, 330-350.

Seidman, L. J., Giuliano, A. J., Meyer, E. C., Addington, J., Cadenhead, K. S., Cannon, T. D., ... Cornblatt, B. A., (2010). Neuropsychology of the prodrome to psychosis in the NAPLS consortium: Relationship to family history and conversion to psychosis. Archives of General Psychiatry, 67, 578-588.

Tandon, N., Montrose, D., Shah, J., Rajarethinam, R. P., Diwadkar, V. A., \& Keshavan, M. S. (2012). Early prodromal symptoms can predict future psychosis in familial high-risk youth. Journal of Psychiatric Research, 46, 105-110.

Tienari, P., Wynne, L. C., Sorri, A., Lahti, I., Moring, J., Naarala, M., ... Wahlberg, K. E. (2004). Genotype-environment interaction in schizophrenia-spectrum disorder: Long-term follow-up study of Finnish adoptees. The British Journal of Psychiatry, 184, 216-222.

van Os, J., Kenis, G., \& Rutten, B. P. (2010). The environment and schizophrenia. Nature, 468, 203-212.

van Os, J., Rutten, B. P., \& Poulton, R. (2008). Gene-environment interactions in schizophrenia: Review of epidemiological findings and future directions. Schizophrenia Bulletin, 34, 1066-1082.

Veling, W., Selten, J. P., Susser, E., Laan, W., Mackenbach, J. P., \& Hoek, H. W. (2007). Discrimination and the incidence of psychotic disorders among ethnic minorities in The Netherlands. International Journal of Epidemiology, 36, 761-768.

How to cite this article: Georgopoulos G, Stowkowy J, Liu L, et al. The role of a family history of psychosis for youth at clinical high risk of psychosis. Early Intervention in Psychiatry. 2019;13:251-256. https://doi.org/10.1111/eip.12471 